\title{
Ensino de Ciências e a Educaçáo Ambiental
}

\section{Science Teaching and Environment Education}

Denise Celeste Godoy de Andrade Rodrigues ${ }^{1}$

\section{Resumo}

O ensino de ciências não deve mais ser visto como transmissão de conceitos, mas sim como construção de conhecimentos para que o processo ensino-aprendizagem tenha sentido e contextualidade. Este artigo tem por objetivo mostrar como aplicar conceitos da disciplina de Física de maneira contextualizada empregando conceitos de educação ambiental. Para isso, trabalhou-se por quatro semanas em seis turmas do primeiro ano do ensino médio de uma escola pública da cidade de Resende-RJ. O tema abodado foi "as formas de transmissão de calor e o meio ambiente", com ênfase no efeito estufa e no aquecimento global. Como resultados, verificou-se que os alunos tiveram bom desenpenho em relação aos conceitos desenvolvidos. Chegou-se ao consenso geral de que algo deve ser feito por cada um de nós para cuidar do nosso ambiente e melhorar as condiçóes de vida da sociedade de forma geral.

Palavras-chave: Ensino de Ciências, Educação Ambiental, Física

\begin{abstract}
Science teaching does not have to be seen as a concepts transmission, but as a construction of knowledge in order to the teaching-learning process has meaning and context. This article has as an objective to show how to apply Physics concepts in a contextualized way, using Environment Education concepts. To do that, we worked for four weeks in six groups of year one of "Ensino Médio" in a public school in Resende - RJ. The theme approached was "ways of warm transmission and environment", emphasizing the stove effect and global warming. As results, we noticed that students had good performances in relation to the concepts developed. It was a general consensus that something must be done by each of us to take care of environment and to improve conditions for life in society in a general way.
\end{abstract}

Keywords: Science Teaching; Environment Education; Physics 


\section{INTRODUÇÁO}

O surgimento de problemas sócio-ambientais como ameaçadores à sobrevivência da vida na Terra é um fenômeno relativamente novo para a humanidade. À medida que o ser humano se distanciou da natureza, passou a encará-la, não mais como um todo em equilíbrio, mas como uma gama de recursos disponíveis, capazes de serem transformados em bens consumíveis. Em poucas décadas, eram muitos os sintomas que indicavam que este modelo não era sustentável. Primeiro, os recursos naturais são finitos e insuficientes para alimentarem as crescentes demandas das sociedades de consumo. Segundo, o bem-estar sedutor e ilusório do consumo, só é vivido por uma pequena parcela da população humana, pois a maioria luta apenas para sobreviver, tendo que enfrentar, agora, os graves problemas ambientais causados pelo próprio modelo econômico. Finalmente, o ser humano é uma espécie entre milhares que depende do todo para sua sobrevivência neste planeta; é a única que tem esta consciência e o poder de intervir benéfica ou maleficamente no ambiente e, portanto, sua responsabilidade é inigualável (PÁDUA, 1999).

Uma das prováveis conseqüências do aumento da concentração de poluentes antropogênicos (provocados pelo homem) na atmosfera é o agravamento do efeito estufa. O aquecimento global, um aumento da temperatura média da superfície terrestre nos últimos 150 anos, é um fenômeno climático de grande proporção. Atualmente, existe um debate em relação às causas deste aumento na temperatura. Já está comprovado que o aquecimento global está se agravando consideravelmente, o que se deve em grande parte às atividades humanas.

Garrett Hardin, ecologista americano, diz que um cidadão do mundo moderno precisa:

- ler e escrever;

- compreender e usar os números; e

- compreender e usar de modo sustentável os complexos sistemas ambientais dos quais fazemos parte.

Diante da temática atual sobre aquecimento global e degradação ambiental, insere-se o presente artigo. Pretendese mostrar a interligaçáo entre o ensino de ciências e a educação ambiental, por meio de uma experiência/relato de caso em sala de aula.

\section{A EDUCAÇÃO AMBIENTAL}

"Estamos num momento critico na história da humanidade, o momento que a humanidade deve decidir o seu futuro, deve escolher o seu futuro, e a escolha é essa: ou formar uma aliança de cuidado do planeta, de cuidarmos uns dos outros e da vida, ou arriscar a nossa extinçấo e a devastação da diversidade da vida". (Carta da Terra, 2007)
Nos últimos anos, a questão ambiental vem se configurando no âmbito das grandes questóes contemporâneas. Expressando a falência da noção de progresso ilimitado, a crise ambiental tem colocado para o mundo contemporâneo o enfrentamento dos riscos produzidos tanto pelo acelerado desenvolvimento das forças produtivas, como pela degradação da biosfera (empobrecimento do patrimônio natural do planeta e da capacidade de recuperação dos ecossistemas). A relaçáo de interdependência entre a sociedade e o meio ambiente, neglicenciada pela modernidade industrial, coloca-se hoje como um dos grandes dilemas do mundo contemporâneo (SENA, 2003).

De acordo com Rothschild (2007), todos podem fazer a sua parte para barrar o problema, sem se intimidar com o seu tamanho. A soma positiva de pequenas açóes, multiplicadas por milhóes de pessoas, pode levar a efeitos decisivos. Neste contexto, a Educação Ambiental se faz indispensável, por ser :

\footnotetext{
"Um processo de reconhecimento de valores e elucidaçáo dos conceitos que levam a desenvolver as habilidades e as atitudes necessárias para entender e apreciar as inter-relaçóes entre os seres humanos, suas culturas e seus meios físicos. A educação ambiental também desenvolve a prática da tomada de decisōes e para as autoformulaçóes de comportamentos sobre os temas relacionados com qualidade do meio ambiente”. (definiçấo da UNESCO de 1983).
}

Definir educação ambiental é tarefa difícil, haja vista as inúmeras definições encontradas em artigos da área. De acordo com definição oficial do Ministério do Meio Ambiente: "Educação ambiental é um processo permanente, no qual os indivíduos e a comunidade tomam consciência do seu meio ambiente e adquirem conhecimentos, valores, habilidades, experiências e determinação que os tornam aptos a agir - individual e coletivamente - e resolver problemas ambientais presentes e futuros" (REVISTA EDUCAÇÃO, 2007).

O CONAMA - Conselho Nacional do Meio Ambiente - define a Educação Ambiental como um processo de formação e informaçáo orientada para o desenvolvimento da consciência crítica sobre as questôes ambientais e de atividades que levem à participação das comunidades na preservação do equilíbrio ambiental (RIO, 2008). No contexto político, científico e cultural da problemática ambiental, a educação ambiental tem uma história nos debates científicos e epistemológicos. A educação ambiental brasileira oferece sólidos elementos para mostrar que, apesar de todas as barreiras, outro tipo de ciência foi, está sendo feita e tende a consolidar-se (REIGOTA, 2007).

Uma pesquisa voltada para o estado da arte da educação ambiental brasileira mostrou que, de 1984 a 2002, foram produzidas no Brasil e no exterior por brasileiros, 1 tese de livre-docência, 45 teses de doutorado e 264 dissertaçóes de 
mestrado (REIGOTA, 2002, 2003).

Independentemente da definição utilizada, a educação ambiental deve ter como base o pensamento crítico e inovador, em qualquer tempo ou lugar, em seus modos formal, não formal e informal, promovendo a transformação e a construção de uma sociedade mais consciente. Sendo a educação ambiental interdisciplinar, esta não deve se basear na transmissão de conteúdos específicos, já que não existe um só conteúdo a ser abordado.

O conteúdo e as estratégias a serem empregadas devem se basear no levantamento da problemática ambiental vivida pela comunidade (escola, bairro, cidade, etc) e que se deseja resolver, mas que para isso é necessário um maior envolvimento da comunidade.

São várias as estratégias que podem ser utilizadas, e a escolha deve ser por aquela que mais se adequou aos objetivos e às características locais: experiência prévia dos envolvidos, o tema abordado e o tempo necessário para sua aplicação. A experiência tem mostrado, no entanto, que a participação ativa da equipe envolvida (aluno, professores, agentes comunitários) favorece sua aprendizagem.

De acordo com Compiani (2007), o uso dos trabalhos de campo por professor e alunos pode orientar o questionamento sobre as velhas disciplinas, aperfeiçoando novas linhas teóricas na tentativa de entendimento mais amplo das relaçóes entre local/global e entre disciplinas escolares científicas e a transversalidade (entendida como educação não disciplinar, conforme defendida por Gallo, 2000). Sob a perspectiva educacional, o campo pode ser um fio condutor para uma disciplina - ou entre disciplinas -, que propicia o melhor desenvolvimento das peculiaridades da prática escolar científica. Um dos pontos de partida é ver o campo como gerador de problemas, ótima situação de ensino problematizadora (COMPIANI, 2007).

O uso integrado de vários instrumentos de gestão ambiental, nos quais se inclui a educação ambiental, possibilita melhor articulação entre açôes e projetos empreendidos, potencializando recursos e resultados. Passa a ser também exigida uma abordagem multidisciplinar, fruto das diferentes formaçóes ecológicas, econômicas e sociais associadas à diversidade de dinâmicas, entre as quais se destacam os conflitos decorrentes do uso dos recursos ambientais e sua conservação.

Segundo Hermes (2004) diversos trabalhos têm sido desenvolvidos com o intuito de integrar a comunidade em açóes de monitoramento em diversos países do mundo. Nos Estados Unidos, a Agência de Proteção Ambiental (EPA, 2007) dá suporte para diversos movimentos voluntários de monitoramento. $\mathrm{Na}$ Austrália, açôes participativas no monitoramento dos recursos hídricos têm sido desenvolvidas com o apoio do governo a partir de um programa denominado Waterwatch Australia (AUSTRALIA, 2007). No Brasil, a Embrapa Meio Ambiente iniciou, a partir de 1999, o trabalho com o objetivo de incorporar a comunidade no monitoramento da qualidade da água, tendo treinado até o final do ano de 2002, cerca de 600 agentes voluntários, sendo 375 na bacia do Rio São Francisco (EMBRAPA, 2003).

\section{O ENSINO DE CIÊNCIAS E A EDUCAÇÃO AMBIENTAL}

Para Loureiro (2006) o ato de educar é uma necessidade de nossa espécie e um fenômeno que deve ser compreendido e analisado para que possa ser eficientemente realizado. É uma dimensão primordial que pode gerar mudanças quando articulada com a realidade sócio-histórica e sóciocultural dos estudantes.

O ensino de ciências é uma das formas de ajudar na construçáo do conhecimento, utilizando recursos e materiais didáticos que permitem aos alunos exercitarem a capacidade de pensar, refletir e tomar decisôes, iniciando assim um processo de amadurecimento. $\mathrm{O}$ professor tem um papel de extrema importância, pois ele deve guiar os alunos, fazendo com que os estudantes participem desta construção, aprendendo a argumentar e exercitar a razão, ele deve questionar e sugerir ao em vez de fornece-lhes respostas definidas ou impor-lhes seus próprios pontos de vista (CARVALHO, 2004).

A Lei de Diretrizes e Bases da Educação Nacional para o Ensino de Ciências, deixa claro no Art. $3^{\circ}$, Parágrafo IV, que todas as escolas deverão garantir a igualdade de acesso para os alunos a uma base nacional comum, que vise estabelecer a relação entre a educação fundamental e a vida cidadã por meio de articulaçóes entre vários dos seus aspectos como: saúde, sexualidade, vida familiar e social, meio ambiente, trabalho, ciência e tecnologia, cultura, e as linguagens (BRASIL, 1996). Neste contexto, os professores de ciências podem contribuir com suas experiências explicando os possíveis transtornos causados no planeta, como por exemplo, o aquecimento global, o problema do lixo, o tratamento do esgoto (GEWANDSZNAJDER; LINHARES 1991) e tentar conscientizar os alunos com uma forma dinâmica e participativa.

\section{METODOLOGIA ADOTADA}

Foram propostos temas de pesquisa da disciplina de Física relacionando as formas de transferência de calor com as questôes ambientais. O objetivo era que os alunos compreendessem os conceitos físicos em questão de forma 
aplicada. Este trabalho foi desenvolvido com seis turmas de primeiro ano do ensino médio de uma escola pública da cidade de Resende, Estado do Rio de Janeiro, no segundo bimestre letivo de 2007.

O trabalho foi dividido em quatro partes: pesquisa dos temas propostos em livros jornais, revistas e internet; elaboração de cartazes, maquetes ou experiências; apresentação dos trabalhos realizados pelos grupos em sala de aula; exibição do filme documentário "Uma Verdade Inconveniente" de GORE (2006), seguido de debate em sala.

Os temas abordados foram: formas de transmissão de calor; efeito estufa; inversão térmica e complicações respiratórias; aquecimento global; mudanças climáticas.

\section{RELATO DA EXPERIÊNCIA EM SALA DE AULA}

Promover discussôes sobre as questôes ambientais possibilita que o aluno reflita de forma crítica sobre os fatos relacionados à existência do homem e sua relação com a natureza, podendo contribuir para mudança de comportamento e atitudes (CURVELO e LATINI, 2007).

O trabalho realizado com os alunos foi desenvolvido sob forma de projeto por quatro semanas. Durante as etapas de pesquisa e confecção de material para apresentação dos trabalhos (etapas 1 e 2) houve orientaçáo e discussão com os alunos, que por estarem motivados, se empenharam da melhor forma possível.

$\mathrm{Na}$ terceira etapa, os trabalhos foram apresentados e o material confeccionado fixado nas salas de aula para apreciação por parte de outras turmas do colégio. Durante as apresentaçóes, os alunos puderam dar suas opinióes acerca dos temas e ajudaram a atribuir nota pela apresentação e empenho dos colegas, resultando em um processo avaliativo conjunto entre professor e alunos.

Dando continuidade ao projeto e visando sensibilizar os alunos para a problemática ambiental e aumentar o conhecimento deles sobre educação ambiental, na última semana do trabalho, foi exibido o documentário "Uma Verdade Inconveniente", seguido de debate por parte dos alunos. O debate teve uma ótima participação dos alunos com perguntas e opinióes sobre o filme.

Cerca de $80 \%$ dos alunos envolvidos nos trabalhos declarararam ter despertado um maior interesse pela disciplina de Física, uma vez que viram aplicaçôes práticas dos conceitos estudados. Em relação ao filme e os aspectos ambientais apresentados, 90\% dos alunos mostraram-se sensibilizado pela realidade apresentada no documentário e tentaram relacionar com fatos ocorridos nos locais por eles frequentados.
Durante as atividades, os alunos citaram locais que, segundo a visão deles, causam impactos ambientais dentro do município, surgindo a idéia de visitá-los posteriormente, o que ainda não se concretizou. Em uma avaliação do projeto, por parte dos alunos, houve consenso geral de que algo deve ser feito por cada um de nós para cuidar do nosso ambiente e melhorar as condiçóes de vida da sociedade de forma geral.

Como frutos deste trabalho, foi realizado no terceiro bimestre letivo de 2007 uma mini feira de ciências, onde os alunos envolvidos buscaram experiências de Física disponíveis em sites na internet e as demonstraram para os alunos das próprias turmas e demais alunos do colégio. Esse fato demonstra que ao se despertar o interesse científico de forma aplicada melhora o aprendizado dos alunos individualmente e coletivamente.

\section{CONCLUSÓES}

Numa visão mais ampla, o educador precisa estabelecer uma comunicação entre o conceito científico e as experiências vividas pelo aluno, respeitando as suas condiçôes culturais. Verificou-se que, durante a confecção dos trabalhos, houve empenho e envolvimento por parte dos alunos, com real aprendizado de conceitos físicos que normalmente são de difícil compreensão.

Além do ensino de física, conseguiu-se a aplicação dos conceitos aprendidos no cotidiano dos alunos, despertando a consciência ambiental de maneira integrada ao ensino de ciências.

\footnotetext{
"É importante que o papel da ciência e da tecnologia nos assuntos humanos seja mais amplamente conhecido, tanto pelos responsáveis por decisóes que ajudam a determinar a política pública quanto pelo público em geral. Será necessário fortalecer as abordagens multidisciplinares existentes e desenvolver mais estudos interdisciplinares entre a comunidade científica e tecnológica e os responsáveis por decisóes e, com a ajuda do público em geral, proporcionar liderança e conhecimentos técnicos-científicos práticos ao conceito de desenvolvimento sustentável.”(Agenda 21).
}

\section{REFERÊNCIAS BIBLIOGRÁFICAS}

AUSTRÁLIA. Disponível em: www.waterwatch.org.au. Acessado em: 10/07/07.

BRASIL. Lei no 9.394, de 20 de dezembro de 1996. Estabelece as Diretrizes e Bases da Educação Nacional. Diário Oficial [da República Federativa do Brasil], Brasília, DF, v. 134, n. 248, 23 dez. 1996. Seção 1, p. 2783427841. 
CARVAlHO, Anna Maria Pessoa de (Org). Ensino de Ciências: unindo a pesquisa e a prática.São Paulo: Pioneira Thomson learning, 2004.

COMPIANI, M. O lugar e as escalas e suas dimensóes horizontal e vertical nos trabalhos práticos: implicaçōes para o ensino de ciências e educação ambiental. Ciência $\&$ Educação, v. 13, n. 1, p. 29-45, 2007.

CURVElO, T. da C. V., LATINI, R.M. Ensino de ciências e ambiente na educaçáo de jovens e adultos. Disponível em: http://www.revistaea.org/artigo. php?idartigo $=536 \&$ class $=02$ acessado em 18/09/08

EMBRAPA Elaboração de um programa de seleção, capacitação e formação de agentes de água voluntários - subprojeto 1: relatório técnico. Jaguariúna: Embrapa Meio Ambiente, 2003. Disponível em: www.embrapa..br. Acessado em 10/07/07.

EPA. Environmental Protection Agency. Disponível em: www.epa.gov/owow/monitoring/vol.html. Acessado em: 23 julho 2007.

GALLO, S. Transversalidade e educação: pensando uma educação não disciplinar. 2. ed. In: ALVES, N. (Org.). O sentido da escola. Rio de Janeiro: DP\&A, 2000. p. 1741.

GEWANDSZNAJDER, Fernando; LINHARES, Sérgio de Vasconcellos. Biologia Programa Completo. 10. ed. São Paulo: Ática, 1991.

GORE, Al. Uma verdade inconveniente. Documentário, EUA, 2006.

HERMES, L.C., FAY,E.F, BUSCHINELLI, C.C.A., SILVA, A.S., FRANÇA E SILVA, E.F. Participação Comunitária em Monitoramento da Qualidade da Água. Circular Técnica 8. Disponível em: www.embrapa.br. Acessado em 15/07/07.

LOUREIRO, C.F.B. Complexidade e Dialética:Contribuiçôes à praxis política e emancipatória em Educação Ambiental. Educ. Soc., Campinas, vol. 27, n. 94 , p. 131-152, jan./abr. 2006

PÁDUA, S.M. (coordenador) Conceitos para se fazer educaçáo ambiental. Secretaria do Meio Ambiente, Coordenadoria de Educação Ambiental. 3a ed..São Paulo: A Secretaria, 1999.
REIGOTA, M. El estado del arte de la educacioón ambiental en Brasil. Tópicos en Educación Ambiental, México, v. 4, n.11, p. 49-62, 2002.

REIGOTA, M. O estado da arte da educaçáo ambiental no Brasil. Sorocaba: Universidade de Sorocaba (Relatório de Pesquisa), 2003.

REIGOTA, M. A. dos S. Ciência e Sustentabilidade: a contribuição da educação ambiental. Avaliação - Revista de Avaliaçáo da Educaçáo Superior, v.12, n. 2, 2007.

Revista Educação, disponível em: http://www. revistaeducacao.com.br/apresenta2.php? edicao $=254 \&$ pag_id=239. Acessado em 15/12/2007.

RIO. Disponível em: http://www.rio.rj.gov.br/multirio/ cime/CE09/CE09_012.html. Acessado em 12/03/2008.

\section{ROTHSCHILD, D. Manual Live Earth de Sobrevivência} ao Aquecimento Global. Ed. Manole. 2007.

SENA, L.B.R. (coordenadora) Educaçáo ambiental : vinte anos de políticas públicas São Paulo (Estado ). Secretaria do Meio Ambiente. Coordenadoria de Planejamento Ambiental Estratégico e Educação Ambiental. / Secretaria de Estado do Meio Ambiente, CPLEA. - - São Paulo : SMA, 2003.

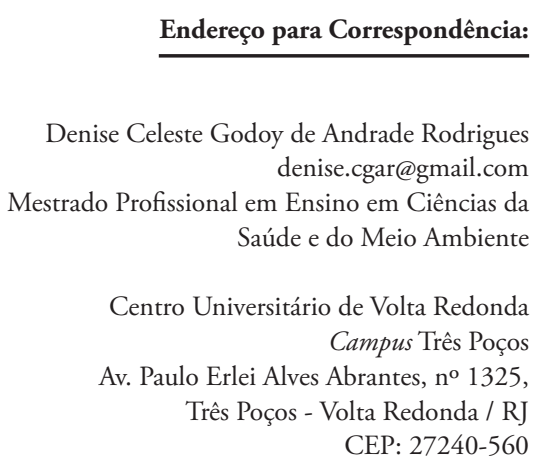

Endereço para Correspondência: de Andrade Rodrigues denise.cgar@gmail.com Saúde e do Meio Ambiente de Volta Redonda
Campus Três Poços CEP: 27240-560 